\title{
NDVI Variations and Its Responses to hydrothermal process in the Naqu River Basin, Qinghai-Tibet Plateau-Alpine Region
}

\author{
Dengming Yan ${ }^{1}$, Shaoming Peng ${ }^{1}$, Xingchen Ding ${ }^{3}$, Zhilei $\mathrm{Yu}^{2 *}$ \\ ${ }^{1}$ Yellow River Engineering Consulting Co., Ltd., Zhengzhou 450003, China \\ ${ }^{2}$ School of Water Conservancy Engineering ZZU, Zhengzhou University, Zhengzhou 450001, China \\ ${ }^{3}$ Science and Technology Innovation Center of Smart Water and Resource Environment, Northeastern University, Shenyang 110819 , \\ China
}

\begin{abstract}
Extensive studies have been conducted over the whole year and various seasons to characterize the temporal and spatial changes in vegetation NDVI. However, there are few studies on the variations of NDVI in different soil hydrothermal processes of the alpine region. So we studied the spatial-temporal variation of vegetation cover and its responses to hydrothermal process in the Qinghai-Tibet Plateau-alpine region. Based on the GIMMS NDVI remote sensing images from 1982 to 2015, the temporal and spatial variations of NDVI in the Naqu river basin at different time scales were studied by using maximum synthesis method, and the linear regression. Results show that the vegetation has an overall degradation trend in the Naqu river basin, with primarily moderate and mild degradation degrees. Completely freezing period, completely melting period and freezing process period are the main vegetation degradation periods.
\end{abstract}

\section{Introduction}

Vegetation, as an important component of terrestrial ecosystem, whose cover change directly reflects the changes of regional ecological environment ${ }^{[1]}$. Located in the Eurasian continent, the Qinghai-Tibet Plateau is known as the "third pole" of the world. Alpine grassland is the main vegetation cover on the plateau ${ }^{[1,2]}$. Alpine grassland is sensitive to environmental change ${ }^{[3]}$. At the same time, due to the dual effects of climate change and human activities, vegetation cover on the plateau has clear seasonal and regional differences ${ }^{[4-6]}$. At present, many studies on vegetation dynamics in the Qinghai-Tibet Plateau focus on its changing trend, with time scales of annual, growing season, seasonal and monthly ${ }^{[7-9]}$. The Qinghai-Tibet Plateau has the largest area of high-altitude permafrost in the world. However, very few studies focus on the dynamic changes of vegetation in different soil hydrothermal processes ${ }^{[7]}$. In this paper, the Naqu River Basin in Nujiang Source Area was selected as a typical study area, and the vegetation dynamic changes of different soil hydrothermal processes in alpine region were discussed. The objectives of this study include: 1) to analyze the temporal and spatial variations of NDVI in Naqu basin in different periods, and 2) to clarify the degree of vegetation degradation and its main degradation periods of different soil hydrothermal processes.

\section{Materials and Methods}

\subsection{NDVI Data and Its Processing}

NDVI data were obtained from the global AVHRR NDVI dataset provided by the National Aeronautics and Space Administration (NASA) Global Inventory Monitoring and Modeling Studies (GIMMS). In this paper, we used the Chinese sub-region sequence from 1982 to 2015 with spatial resolution of $8 \mathrm{~km} * 8 \mathrm{~km}$ and temporal resolution of 15 D. Compared with other data, this data has advantages of small error, high accuracy and long period, and has been widely used in studies about global and regional large-scale vegetation cover change ${ }^{[4,10,11]}$. The maximum value composition (MVC) method was used to extract the lager value of two HALF-MONTHLY NDVI values as the NDVI value of this month based on ArcGIS 10.2 software. Then, the annual NDVI values from 1982 to 2015 were calculated based on the monthly NDVI value.

\subsection{Division of freezing-thawing period}

Based on the characteristics of the active layer in permafrost region of the Naqu basin, the soil hydrothermal process was divided into four stages: freezing period (November-December), frozen period (January-April), thawing period (May-June), and thawed period (July-October). 


\subsection{Trend analysis}

Univariate linear regression can make use of the temporal variability in each grid pixel to reflect the overall spatial variability, and comprehensively reflect the evolution of regional spatial-temporal pattern ${ }^{[12]}$. Therefore, the changing trend of each element in Naqu basin during 1982-2015 was analyzed using linear regression. The formula is as follows:

$$
\text { Slope }=\frac{n \times \sum_{i=1}^{n}\left(i \times X_{i}\right)-\sum_{i=1}^{n} i \sum_{i=1}^{n} X_{i}}{n \times \sum_{i=1}^{n} i^{2}-\left(\sum_{i=1}^{n} i\right)^{2}}
$$

Where, Slope is the trend slope of the corresponding factors, $n$ is the number of years in the study period ( $n=$ 34 ), and $X_{i}$ is the value of the corresponding changing factor in the $i^{\text {th }}$ year. Slope $>0$ indicates that the corresponding factors in the grid are increasing in the study period, otherwise they are decreasing, and the larger the absolute value, the more obvious the change is.

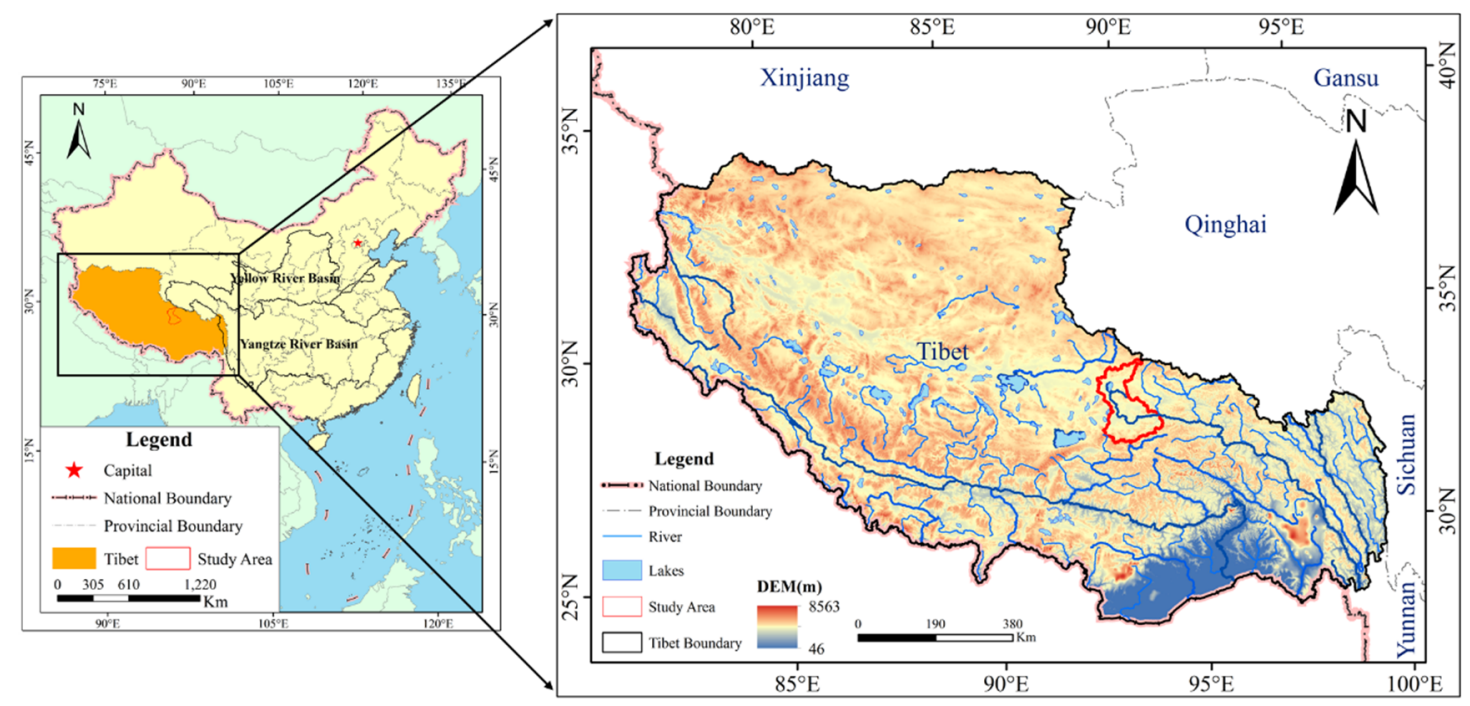

Figure 1. The Geographical Location and the study area.

\section{Study Area}

The Naqu River Basin (Figure. 1) is located in the Naqu area of Tibet Autonomous Region of China and in the central region of the Qinghai-Tibet Plateau. The geographic coordinates are $91^{\circ} 8^{\prime} \sim 92^{\circ} 1^{\prime} \mathrm{E}$ and $30^{\circ} 48^{\prime}$ $\sim 32^{\circ} 44^{\prime} \mathrm{N}$. The basin area is about $16967.4 \mathrm{~km}^{2}$, with an average altitude of $4799 \mathrm{~m}$. The vegetation in the basin has a uniform structure which belongs to the alpine vegetation type of the Qinghai-Tibet Plateau. 94\% of the vegetation is alpine meadow, and the remaining is alpine vegetation and grassland.

\section{Results and discussion}

\subsection{Interannual and Decadal Variation patterns of NDVI}

The grassland coverage in Naqu basin showed an insignificant $(\mathrm{P}<0.05)$ downward trend with a decreasing rate of $0.35 \% / 10 \mathrm{a}$ (Figure 2(a)). The annual average NDVI value was $29.62 \%$. The grassland had the highest coverage in 1988, with an average NDVI value of $32.49 \%$, and the lowest coverage in 2015, with an average NDVI value of $27.51 \%$. The decadal change showed an overall "rising-falling" trend (Figure 2(b)). In the 1980s, the average NDVI in the basin was $29.75 \%$, and the overall vegetation coverage showed an increasing trend, with an average increasing rate of $0.53 \% / 10 \mathrm{a}$. In the $1990 \mathrm{~s}$ and after, the average value of NDVI in the basin was $29.54 \%$, and the overall vegetation cover showed a decreasing trend, with an average declining rate of $0.71 \% / 10 \mathrm{a}$. In addition, the grassland had the highest coverage in the 1990 s, with the average NDVI of about $30.29 \%$. In the 21 th century, the grassland coverage reached the lowest level, with the average NDVI of about $29.16 \%$. 

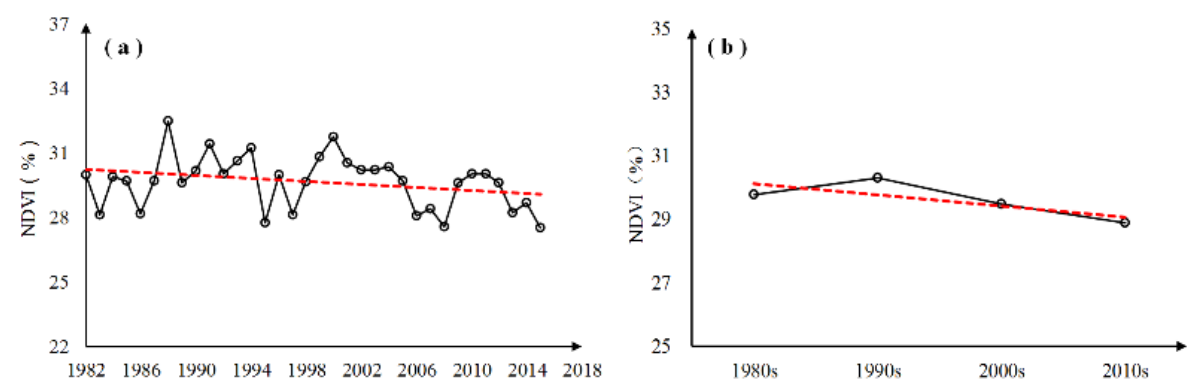

Figure 2. NDVI trends in different periods of time in the Naqu Basin (a: inter-annuals; b: different decades).

\subsection{Temporal Variation of NDVI in Different Freezing-Thawing Periods}

With the change of soil hydrothermal process, the freezing-thawing period of the soil was changing constantly (Figure 3). In different freezing-thawing periods, NDVI in the basin changed notably, showing a single peak change on the whole. When the surface soil was completely frozen, the soil water content tended to be stable, ranging from $10 \%$ to $11 \%$, and the annual average value of NDVI in this stage was $16.76 \%$.

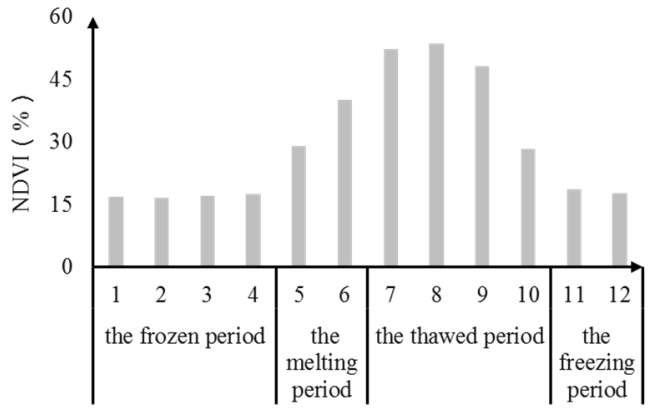

Figure 3. Changes of the NDVI in freezing-thawing periods of the Naqu basin.

In addition, because the soil active layer had a negative temperature, which is unsuited to the growth of vegetation in the basin, the NDVI value was low during January to April, and reached the lowest value in February $(16.55 \%)$. With the increase of temperature and precipitation in the basin, in May, the surface soil began
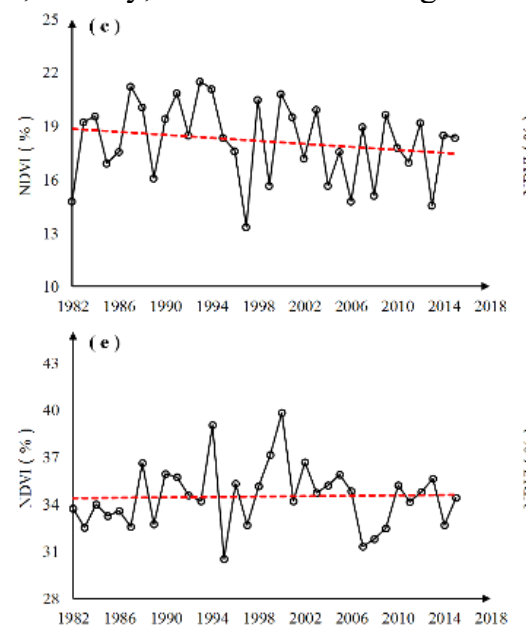

to melt, soil moisture increased, and the solar radiation absorbability was strengthened. In addition, the surface albedo was smaller, which made the short-wave solar radiation absorbed by the surface larger than the longwave radiation emitted by the surface. The vegetation grew rapidly and the NDVI value increased rapidly, with the average increasing to $34.47 \%$. From July to October, the surface soil was completely ablated, and the soil water content fluctuated sharply in a higher range. NDVI peaked synchronously at this stage, with an overall average of $45.16 \%$, and reached its maximum in August $(53.48 \%)$. From November to December, the short-wave solar radiation received by the soil was less than the longwave radiation. The temperature dropped sharply to near zero and soil moisture decreased synchronously. The soil gradually enters the freezing state and the vegetation withers. The corresponding NDVI value decreased, with an average of only $18.14 \%$.

From the perspective of NDVI annual mean change, grassland coverage changed significantly in different freezing-thawing periods. Figure 4 ((c) (f)) shows the trend of vegetation change in alpine regions in Different Soil Hydrothermal processes. The grassland coverage declined during the frozen period, the thawed period and the freezing period. The most obvious decline was in the frozen period, with a significant decrease of $0.59 \% / 10 \mathrm{a}$ (P $<0.05)$. During the melting process, the grassland coverage increased slightly, with an increase of $0.071 \% / 10 \mathrm{a}$. It is further confirmed that the change of vegetation coverage in the basin is closely related to the dynamic change of soil water and heat.

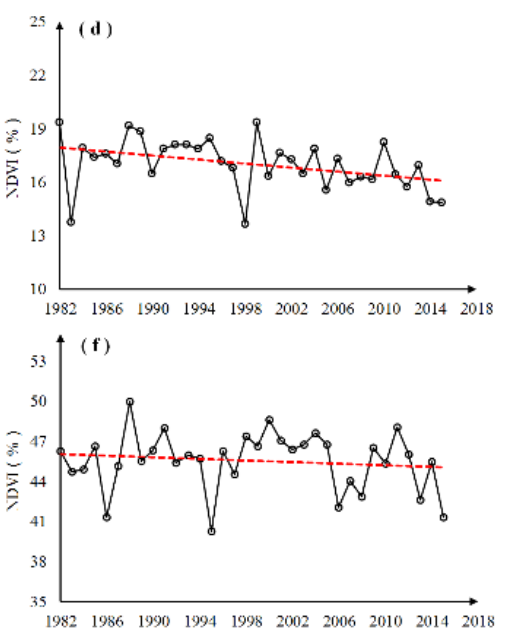

Figure 4. Trends of the NDVI in different periods of the Naqu basin (The Figure. -c presents all freezed periods from Jan. to Apr., Figure. $-\mathrm{d}$ is the melting process from May to Jun., Figure. -e is complete period during Jul to Aug., and Figure. -f is the freezing process over Nov. to Dec.). 


\subsection{NDVI Spatial Distribution of Multi-year and Different decades}

According to the spatial distribution characteristics of the NDVI in the Naqu basin (Table 1), the vegetation has the highest coverage in the middle reaches of the basin from 1982 to 2015 , with the average NDVI of $32.29 \%$; the grassland coverage in the lower reaches was lower than middle reaches, with the average NDVI of about $30.10 \%$; and the vegetation growth in the upper reaches was the worst, with the average NDVI of $27.09 \%$. From the spatial distribution characteristics of NDVI mean in Naqu basin in different years (Table 1), the spatial distribution characteristics of grassland cover in different years are basically consistent with the multi-year average. Namely, the grassland coverage in the middle reaches was the highest, followed by the downstream and the upstream. Among them, the grassland coverage in the middle reaches of Naqu basin in the 1990s was the highest, with the average NDVI of about $33.07 \%$. Since the $21^{\text {th }}$ century, the grassland coverage in the basin has been decreasing, and the vegetation coverage in the upper reaches of the basin is the lowest, with an average NDVI of about $26.63 \%$.

Table 1. Mean NDVI values in different periods and various regions (Unit: \%).

\begin{tabular}{cccccc}
\hline \multirow{2}{*}{ Various decadcal periods } & \multirow{2}{*}{ The whole Naqu Basin } & \multicolumn{3}{c}{ Different regions } \\
\cline { 3 - 5 } & & Upstream & Middle reaches & Downstream \\
\hline $1982-2015$ & 29.82 & 27.09 & 32.29 & 30.10 \\
$1982-1990$ & 29.75 & 27.10 & 32.45 & 29.81 \\
$1991-2000$ & 30.29 & & 27.64 & 33.07 & 30.09 \\
$2001-2010$ & 29.44 & 26.87 & 32.00 & 29.65 \\
$2011-2015$ & 28.09 & 26.38 & 31.01 & 29.68 \\
\hline
\end{tabular}

\subsection{Spatial Distribution of NDVI in Different Freezing-Thawing Periods}

There are clear spatial variabilities of vegetation growth in the basin during different freezing-thawing periods. On the whole, the distribution characteristics of vegetation cover in the upper, middle and lower reaches of the basin were consistent during the freezing-thawing periods. Namely, the vegetation growth in the middle reaches of the basin was the best (NDVI was 18\% - 50\%), followed by the downstream (NDVI was $16 \%-48 \%$ ) and the vegetation coverage in the upper reaches was relatively poor (NDVI was $17 \%-41 \%$ ). According to the mean value of NDVI spatial distribution in different freezingthawing periods, the vegetation coverage in the basin was the lowest, with the average NDVI value of about $17 \%$. During the thawing period, the vegetation coverage increases dramatically, and the average value of NDVI increased rapidly to $35 \%$. During the thawed period, under the suitable water and heat conditions, the vegetation coverage in the basin reached the highest level in a year, and the average value of NDVI was $46 \%$. After that, soil began to freeze, and vegetation cover decreased significantly in this process, with an average NDVI value of $18 \%$.

\subsection{The variation of multiyear NDVI slope}

The vegetation in the basin was degraded as a whole, with a total degraded area of $13320 \mathrm{~km}^{2}$, accounting for $78 \%$ of the total basin area (Table 2). The degree of vegetation degradation was mainly moderate and mild. The area of vegetation degradation was about $12186 \mathrm{~km}^{2}$, accounting for $71 \%$ of the corresponding area. The area of severe degradation and extraordinarily serious vegetation degradation was about $1134 \mathrm{~km}^{2}$, accounting for only $7 \%$ of the total area.

Table 2. The slope trend of NDVI in the Naqu Basin.

\begin{tabular}{|c|c|c|c|c|c|}
\hline ID & NDVI Changes & Slope Range & $\begin{array}{l}\text { Area } \\
\left(\mathrm{km}^{2}\right)\end{array}$ & $\begin{array}{c}\text { Propotion } \\
(\%)\end{array}$ & $\begin{array}{c}\text { Decrease / } \\
\text { Increase } \\
(\%)\end{array}$ \\
\hline 1 & $\begin{array}{l}\text { Most severe } \\
\text { decrease }\end{array}$ & slope $<-0.0031$ & 131 & 0.77 & \\
\hline 2 & Severe decrease & $-0.0031<$ slope $<-0.0021$ & 1003 & 5.86 & 77.79 \\
\hline 3 & Light decrease & $-0.0021<$ slope $<-0.0011$ & 5927 & 34.61 & \\
\hline 4 & Slight decrease & $-0.0011<$ slope $<-0.0001$ & 6259 & 36.55 & \\
\hline 5 & Nearly unchanged & $-0.0001<$ slope $<0.0009$ & 2831 & 16.53 & 16.53 \\
\hline 6 & Slight increase & $0.0009<$ slope $<0.0019$ & 816 & 4.77 & \\
\hline 7 & Light increase & $0.0019<$ slope $<0.0029$ & 103 & 0.60 & $\underline{5.68}$ \\
\hline 8 & Evident increase & slope $>0.0029$ & 53 & 0.31 & \\
\hline
\end{tabular}

It is worth pointing out that the degree of vegetation degradation in the basin had obvious regional variabilities. The extraordinarily seriously and slightly degraded vegetation areas mainly distributed in the upstream areas, with degraded areas accounting for about $2 \%$ and $41 \%$ of the total upstream area respectively; the seriously 
degraded areas were mainly in the middle reaches, with degraded areas accounting for about $13 \%$ of the total area of the middle reaches; and more than $50 \%$ of the slightly degraded areas were located in the downstream. In addition, the vegetation coverage in some areas of the basin has been improved in a variety of degrees. The total area of the corresponding improvement area was about $972 \mathrm{~km}^{2}$, which accounts for less than $6 \%$ of the total area of the basin. Among them, the slightly improved vegetation area is about $789 \mathrm{~km}^{2}$, accounting for about $5 \%$ of the total area, mainly distributed in the middle reaches; the total area of moderately and significantly improved vegetation was only about $150 \mathrm{~km}^{2}$, less than $1 \%$ of the basin area, mainly distributed in the upper and middle reaches.

Table 3. Variation of NDVI trend in different freezing-thawing periods.

\begin{tabular}{|c|c|c|c|c|c|c|}
\hline $\begin{array}{l}\text { Different } \\
\text { Freezing- } \\
\text { Thawing } \\
\text { Periods }\end{array}$ & ID & NDVI Changes & Slope Range & $\begin{array}{c}\text { Area } \\
\left(\mathrm{km}^{2}\right)\end{array}$ & $\begin{array}{c}\text { Propotion } \\
(\%)\end{array}$ & $\begin{array}{c}\text { Decrease / } \\
\text { Increase } \\
(\%)\end{array}$ \\
\hline \multirow{8}{*}{$\begin{array}{l}\text { Frozen } \\
\text { period }\end{array}$} & 1 & Most severe decrease & slope $<-0.0031$ & 156 & 0.91 & \multirow{4}{*}{82.25} \\
\hline & 2 & Severe decrease & $-0.0031<$ slope $<-0.0021$ & 81 & 0.47 & \\
\hline & 3 & Light decrease & $-0.0021<$ slope $<-0.0011$ & 2133 & 12.46 & \\
\hline & 4 & Slight decrease & $-0.0011<$ slope $<-0.0001$ & 11713 & 68.41 & \\
\hline & 5 & Nearly unchanged & $-0.0001<$ slope $<0.0009$ & 2906 & 16.97 & \multirow[t]{2}{*}{16.97} \\
\hline & 6 & Slight increase & $0.0009<$ slope $<0.0019$ & 134 & 0.78 & \\
\hline & 7 & Light increase & $0.0019<$ slope $<0.0029$ & - & - & \multirow[t]{2}{*}{$\underline{0.78}$} \\
\hline & 8 & Evident increase & slope $>0.0029$ & - & - & \\
\hline \multirow{8}{*}{$\begin{array}{l}\text { Thawing } \\
\text { period }\end{array}$} & 1 & Most severe decrease & slope $<-0.0031$ & - & - & \multirow{3}{*}{23.65} \\
\hline & 2 & Severe decrease & $-0.0031<$ slope $<-0.0021$ & - & - & \\
\hline & 3 & Light decrease & $-0.0021<$ slope $<-0.0011$ & 449 & 2.62 & \\
\hline & 4 & Slight decrease & $-0.0011<$ slope $<-0.0001$ & 3601 & 21.03 & \multirow{3}{*}{55.94} \\
\hline & 5 & Nearly unchanged & $-0.0001<$ slope $<0.0009$ & 9579 & 55.94 & \\
\hline & 6 & Slight increase & $0.0009<$ slope $<0.0019$ & 2672 & 15.60 & \\
\hline & 7 & Light increase & $0.0019<$ slope $<0.0029$ & 583 & 3.40 & 20.10 \\
\hline & 8 & Evident increase & slope $>0.0029$ & 186 & 1.09 & \multirow{5}{*}{77.62} \\
\hline \multirow{8}{*}{$\begin{array}{l}\text { Thawed } \\
\text { period }\end{array}$} & 1 & Most severe decrease & slope $<-0.0031$ & 131 & 0.77 & \\
\hline & 2 & Severe decrease & $-0.0031<$ slope $<-0.0021$ & 1003 & 5.86 & \\
\hline & 3 & Light decrease & $-0.0021<$ slope $<-0.0011$ & 5955 & 34.78 & \\
\hline & 4 & Slight decrease & $-0.0011<$ slope $<-0.0001$ & 6202 & 36.22 & \\
\hline & 5 & Nearly unchanged & $-0.0001<$ slope $<0.0009$ & 2831 & 16.53 & \multirow[t]{2}{*}{16.53} \\
\hline & 6 & Slight increase & $0.0009<$ slope $<0.0019$ & 816 & 4.77 & \\
\hline & 7 & Light increase & $0.0019<$ slope $<0.0029$ & 132 & 0.77 & 5.85 \\
\hline & 8 & Evident increase & slope $>0.0029$ & 53 & 0.31 & \\
\hline \multirow{8}{*}{$\begin{array}{l}\text { Freezing } \\
\text { period }\end{array}$} & 1 & Most severe decrease & slope $<-0.0031$ & - & - & \multirow{4}{*}{75.54} \\
\hline & 2 & Severe decrease & $-0.0031<$ slope $<-0.0021$ & 156 & 0.91 & \\
\hline & 3 & Light decrease & $-0.0021<$ slope $<-0.0011$ & 1114 & 6.51 & \\
\hline & 4 & Slight decrease & $-0.0011<$ slope $<-0.0001$ & 11665 & 68.12 & \\
\hline & 5 & Nearly unchanged & $-0.0001<$ slope $<0.0009$ & 4028 & 23.52 & \multirow[t]{2}{*}{23.52} \\
\hline & 6 & Slight increase & $0.0009<$ slope $<0.0019$ & 160 & 0.93 & \\
\hline & 7 & Light increase & $0.0019<$ slope $<0.0029$ & - & - & \multirow{2}{*}{$\underline{0.93}$} \\
\hline & 8 & Evident increase & slope $>0.0029$ & 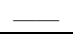 & - & \\
\hline
\end{tabular}

\subsection{Degradation degree in different freezing- thawing periods}

The vegetation had different degradation degrees in Naqu basin during different freezing-thawing periods (Table 3). Frozen period, thawed period and freezing period are the main periods in terms of vegetation degradation. The corresponding areas of vegetation degradation are about $14803 \mathrm{~km}^{2}, 13291 \mathrm{~km}^{2}$ and $12935 \mathrm{~km}^{2}$, accounting for $82 \%, 78 \%$ and $76 \%$ of basin area respectively. The vegetation in frozen period and freezing period had mainly slight degradation, with a degraded area of 11713 $\mathrm{km}^{2}$ and $11665 \mathrm{~km}^{2}$ respectively, each accounting for about $68 \%$ of the total area, while the seriously and extremely seriously degraded areas were relatively small, about $237 \mathrm{~km}^{2}$ and $156 \mathrm{~km}^{2}$, accounting for about $1 \%$ of the total area, respectively. During the thawed period, vegetation degradation was mainly mild and moderate.

By analyzing the spatial and temporal changes of the NDVI, as a whole, the vegetation cover of the Naqu River Basin was decreasing during 1982 to 2015 . The dynamic changes of the vegetation cover were various in different periods. The vegetation increased before 2000, and decreased after 2000. During different freezing -thawing periods, the vegetation cover of the basin showed a singlepeak change. The frozen soil began to melt, while the vegetation cover began to increase; it reached the max

\section{Conclusions}

By analyzing the spatial and temporal changes of the NDVI, as a whole, the vegetation cover of the Naqu River Basin was decreasing during 1982 to 2015 . The dynamic changes of the vegetation cover were various in different periods. The vegetation increased before 2000, and decreased after 2000. During different freezing -thawing periods, the vegetation cover of the basin showed a singlepeak change. The frozen soil began to melt, while the vegetation cover began to increase; it reached the max value during the complete melting period of the frozen soil. In space, there were the significant regional differences in vegetation cover of the Naqu basin. In 
different periods, whether it is interannual, chronological or different freezing and thawing period, vegetation cover was higher in the middle basin than in the upstream and downstream. According to the NDVI change rate, the vegetation cover variation was degenerate in the whole. the vegetation has an overall degradation trend, with primarily moderate and mild degradation degrees. Completely freezing period, completely melting period and freezing process period are the main vegetation degradation periods.

\section{Acknowledgments}

This paper was supported by National Natural Science Foundation of China (Grant No. 51879240).

\section{References}

1. Xin ZB, Xu JX, Zheng W. Spatiotemporal variations of vegetation cover on the Chinese Loess Plateau (1981-2006): Impacts of climate changes and human activities. Science in China, 2008, 51: 67-78.

2. Zhou T, Zhang YS, Gao HF, et al. Relationship between vegetation index and ground surface temperature on the Tibetan Plateau alpine grassland.Journal of Glaciology and Geocryology, 2015, 37(1): 58-69.(in Chinese)

3. Li HQ, Li YN, Zhang FW, et al. Variations of production and water use efficiency of the vegetation in alpine meadow. Journal of Glaciology and Geocryology. 2013, 35: 475-482. (in Chinese)

4. Liu JH, Gao JX, Wang WJ. Variations of Vegetation Coverage and Its Relations to Global Climate Changes on the Tibetan Plateau during 1981-2005. Journal of Mountain Science, 2013, 31: 234-242. (in Chinese)

5. Li ZT, Kafatos M. Interannual variability of vegetation in the United States and its relation to El Niño/Southern Oscillation. REMOTE SENS ENVIRON, 2000, 71: 239-247.

6. Zhou W, Gang CC, Li JL, et al. Spatial-temporal dynamics of grassland coverage and its response to climate change in China during 1982-2010. ACTA GEOGRAPHICA SINICA 2014, 69: 15-30. (in Chinese)

7. Hu H, Wang G, Wang Y, et al. Response of soil heatwater processes to vegetation cover on the typical permafrost and seasonally frozen soil in the headwaters of the Yangtze and Yellow Rivers. Chinese Science Bulletin, 2009, 54(7):1225-1233. (in Chinese)

8. Li H, Wei X, Zhou H. Rain-use efficiency and NDVIbased assessment of karst ecosystem degradation or recovery: A case study in Guangxi, China. Environmental Earth Sciences 2015, 74: 977-984.

9. Wang K, Li Z, Qiu Y, et al. Snow effects on alpine vegetation in the Qinghai-Tibetan Plateau.
INTERNATIONAL JOURNAL OF DIGITAL EARTH, 2015, 8: 3331-3344.

10. KOBAYASHI, Hideki, Dennis G. Atmospheric conditions for monitoring the long-term vegetation dynamics in the Amazon using normalized difference vegetation index. REMOTE SENS ENVIRON, 2005, 97: 519-525.

11. GOETZ, Scott J, FISKE, Gregory J, BUNN, Andrew G. Using satellite time-series data sets to analyze fire disturbance and forest recovery across Canada. REMOTE SENS ENVIRON, 2006, 101: 352-365.

12. Yuan M X, Zou L, Lin A W, et al. Analyzing dynamic vegetation change and response to climatic factors in Hubei Province, China. Acta Ecologica Sinica, 2016, 36(17): 5315-5323. (in Chinese) 